\title{
Allocation in life cycle assessment of lignin
}

\author{
Frida Hermansson ${ }^{1}$ (D) $\cdot$ Matty Janssen ${ }^{1} \cdot$ Magdalena Svanström $^{1}$
}

Received: 16 October 2019 / Accepted: 15 May 2020 / Published online: 5 June 2020

(C) The Author(s) 2020

\begin{abstract}
Purpose Lignin extraction in pulp mills and biorefineries are emerging technologies. Lignin is always the product of a multioutput process. Assessing such processes using life cycle assessment (LCA) requires the environmental impacts to be divided between the co-products of the system, referred to as allocation. This article explores different allocation approaches for lignin and illustrates the influence of the choice of allocation approach on the climate impact in a case study.

Method Ten different applicable allocation methods were found in literature and two more were developed. Lignin production in a Kraft pulp mill using the LignoBoost process for lignin extraction was selected as a study object for the case study, and due to limited data availability only climate impact was considered. A cradle-to-gate LCA was done for the study object, and all of the twelve allocation approaches were applied; for eight of the methods, factors that strongly influence the results were identified and varied. Finally, the results were put in the context of cradle-to-grave LCAs from literature for different possible uses of lignin to give an indication of how important the choice of allocation approach can be when assessing lignin as a substitute for other raw materials.

Results and discussion Results show that all allocation approaches tested were applicable to the special case of lignin, but each one of them comes with inherent challenges. Factors that often have a large impact on the results are (1) market and price of different outputs; (2) what is seen as the main product or the driver of the system or system changes; (3) what the surrounding system looks like and hence what other products will be displaced by outputs. These factors can be particularly challenging in prospective studies as such studies are future-oriented and consider systems that do not yet exist. Finally, the results show that the choice of allocation could have a significant influence on the climate impact on the cradle-to-grave climate impact of the final product.

Conclusions We recommend for LCAs of lignin-based technologies that allocation methods are very carefully selected based on the goal and scope of the study and that when relevant, several methods are applied and factors are varied within them in a sensitivity analysis. In particular, the driver(s) of the system's existence or of changes to it, sometimes reflected in market prices of outputs, should be carefully considered.
\end{abstract}

Keywords LCA $\cdot$ Lignin $\cdot$ Multi-output $\cdot$ Climate impact $\cdot$ Allocation $\cdot$ Emerging technologies

\section{Introduction and background}

Responsible editor: Matthias Finkbeiner

Electronic supplementary material The online version of this article (https://doi.org/10.1007/s11367-020-01770-4) contains supplementary material, which is available to authorized users.

Frida Hermansson

Frida.Hermansson@Chalmers.se

1 Division of Environmental Systems Analysis, Department of Technology Management and Economics, Chalmers University of Technology, SE-412 96 Gothenburg, Sweden
Lignin is the world's most common natural aromatic polymer and is found in plants where it provides stiffness to the stems (Ragauskas et al. 2014). While today mainly used for internal energy use, it can be extracted from the side streams of biorefineries (e.g. ethanol production plants (Modahl et al. 2015)) and pulp mills (e.g. from the black liquor in a Kraft pulp mill (Culbertson et al. 2016)). Recently, lignin has received more and more attention as a possible future renewable raw material for products such as adhesives (e.g. replacing urea-formaldehyde, see Yuan and Guo (2017)) and carbon fibers (e.g. replacing polyacrylonitrile (PAN), see the LIBRE (2016) and GreenLight (2016) projects). In such technology 
development efforts, it is important to make sure that the overall resulting environmental performance is also improved. Life cycle assessment (LCA) is a method that can be used to identify opportunities to improve the environmental performance of a product throughout its life cycle, from the raw material extraction to its end of life. Therefore, it can be a useful tool to inform development of various lignin-based products, provided that the assessment can deal with challenges related to e.g. multi-output processes and uncertainties in emerging product systems. Lignin is always a product of a multi-output process. Therefore, there are inherent methodological problems in LCA when assessing its environmental performance, namely, how the environmental burdens of the system should be allocated to lignin and its co-products. It has previously been recognized that the choice of allocation approach in LCAs of lignin is crucial (Secchi et al. 2019) because it can strongly affect the environmental performance of the end product, as was also shown for lignin-based carbon fibers by Hermansson et al. (2019). However, lignin as a raw material for applications such as carbon fibers or adhesives are emerging technologies still in the development phase. Assessing emerging technologies using LCA (sometimes referred to as prospective LCA (Arvidsson et al. 2018)) is challenging as data availability for the technology is low and it is difficult to predict both how the technology and its surrounding systems will develop, especially if many years can be expected to be needed before its large-scale introduction on the market. This makes the choice of allocation method in LCAs of lignin even more difficult as some of these uncertain factors affect also how allocation should be done.

Two main guidelines for LCA practitioners to follow are ISO 14044:2006 (International Organization of Standardization 2006) and the ILCD guidelines (European Commission Joint Research Center 2010). These guidelines provide a hierarchy for approaches to solving allocation issues for multi-output processes. The hierarchy is divided into three parts, in the following order: subdivision, system expansion, and allocation. Subdivision means that more detailed data are collected for each of the mono-functional processes in the system (i.e. allocation is avoided by increasing the level of detail in the description of the system). Processes generating lignin, such as biorefineries, are, however, often so integrated that this cannot be done in a meaningful way (Njakou Djomo et al. 2017). System expansion originally (as in the ISO 14044:2006 guidelines) meant that the boundaries of the system are expanded to include all the production of all functions (for example all product outputs) provided by the system so that in effect, no partitioning needs to be made (i.e. the functional unit is extended to include all functions of the system studied). The ILCD guidelines, however, suggest a method called system expansion by substitution, which means that the system is expanded to include the functions replaced by the co-products of the system with negated impacts, which is a more useful approach when the intention is to assess a single product from a multi-output process rather than the entire system. However, a particular challenge arises if the expansion or the alternative production is also a multifunctional process (as for example biorefineries by definition are) because another allocation problem is then introduced as a consequence of avoiding the original one (Ekvall and Finnveden 2001). This cascading effect can carry on in several steps making an LCA cumbersome and its results difficult to interpret. Both guidelines say that, when allocation cannot be avoided by the use of subdivision and system expansion (by substitution), allocation should primarily be based on physical relationships, such as mass, energy, or volume. If a physical relationship cannot be established, the economic value of the co-products can be used as a basis for allocation. Some argue that physical relationships do not in themselves describe the driver of any process, but that economic revenues do. As a consequence, allocation based on economic value can be seen as more relevant than allocation based on physical relationships (see for example Huppes and Schneider (1994)). This argument is however not supported in the guidelines.

In spite of the hierarchy presented in the ISO 14044:2006 and ILCD guidelines, there seems to be no consensus on how allocation should be dealt with in practice for ligningenerating processes as approaches used in published studies vary greatly. For example, Das (2011) uses mass-based allocation, Bernier et al. (2013) compare emissions before and after lignin extraction was added to a mill, and Culbertson et al. (2016) used system expansion by substitution as well as mass-based and economic allocation. During the work in a previous study on the potential environmental impact of lignin-based carbon fibers, it was found that the allocation method used for the lignin-generating processes could be of great importance for the resulting environmental impact of lignin (Hermansson et al. (2019)). In that study, LCA results from different literature sources were explored, applying three different allocation methods to them (mass-based allocation, economic allocation, and a so-called consequential approach (in the present paper referred to as a marginal approach)). This follow-up study aimed to gather additional methods and to further develop allocation options for lignin-generating processes, as well as to apply them in a case study to see if that is practically possible and to show their effect on the results. It also aimed to assess the significance of the choice of allocation approach in a cradle-to-grave perspective. As the choice of allocation method is heavily dependent on the context of the study as well as data availability, it is deemed outside the scope of this paper to provide specific recommendations on which method to apply in different cases. Instead, the authors' intent is that others can use this wide selection of allocation methods as a guide to what could be a suitable method in their specific context. Furthermore, since lignin-based technologies are just emerging, particular focus was put in the study on 
factors that may need to be varied because of uncertainties related to these technologies or to the surrounding system.

\section{Method}

The methodology used in the study consisted of three parts. The first was an initial planning of a case study and identification and development of suitable allocation methods, which was done in parallel and iteratively. The second part was to perform the cradle-to-gate LCA case study, and the third part was to put the results in a cradle-to-grave context. The allocation methods and the case study system (a Kraft pulp mill with LignoBoost lignin-extraction as described by Culbertson et al. (2016)) are presented in this section (although they could partially be seen as results of the study), while results from the case study and the cradle-to-grave contextualization are found in the results and discussion section. Values used in the different allocation approaches are found in the Supplementary Material.

\subsection{Allocation approaches}

As the purpose of this study is not to assess which allocation methods are more appropriate for different contexts but to present a wide range of different methods in order to illustrate the possible impact these could have, no specific selections criteria were applied. Most of the employed allocation approaches had been gathered in a previous study, a metaanalysis of already published LCA studies to identify hotspots and identify opportunities and challenges for lignin-based carbon fibers in carbon fiber reinforced polymers (CFRPs) (see Hermansson et al. (2019) for more information). In the current study, additional approaches that have been suggested for biorefinery systems were collected from the literature. Additionally, two allocation approaches were developed by the authors of this paper. A brief description of all twelve employed allocation approaches is found in Table 1, and these are further described in Sects. 2.1.1-2.1.12. The order roughly follows the hierarchy postulated by the guideline documents, as described earlier. Note that not all methods are applicable in all contexts. For example, some are based on changing a mill to add lignin extraction, while others are based on a mill that already extracts lignin.

\subsubsection{Changes made to the mill}

This allocation method was developed by the authors in this study. The rationale behind this method is that when lignin extraction is introduced to an existing process that was originally built and run for other purposes, the impact of lignin should not be higher than the additional impact of the added lignin extraction process and the replacement of the loss of energy from the system that this change results in (as lignin is otherwise burnt for internal energy use at the Kraft pulp mill). The method assumes that the system can be subdivided in this way (i.e. data is available for the lignin extraction and for the loss of energy) and can be seen as a pragmatic approach to subdivision, therefore in essence adhering to the ISO 14044:2006 and ILCD guidelines. While the results from this approach will likely be similar to the results from using the approach described in Sect. 2.1.2, we argue that this approach is easier to apply because it can be applied to any Kraft pulp system where lignin extraction is introduced and is not dependent on having access to a data set for the whole system for both before and after the introduction of the lignin extraction. A drawback with this method, however, is that it does not consider any potential debottlenecking of the recovery boiler resulting in an increased pulp production (Axelsson et al. 2006). In fact, lignin extraction in a Kraft pulp mill may in reality be introduced primarily as a means to increase pulp production, and this approach does not take that into account. If the reason for changing the system is in fact only to increase the pulp production capacity, the lignin extraction impact could in its entirety be allocated to the pulp. Such an approach is described in Sect. 2.1.3. If one of the reasons is to extract lignin to sell and generate revenue for the plant, the impact could be allocated to the lignin in the way suggested here.

\subsubsection{Marginal approach}

This approach is suggested by Bernier et al. (2013) and considers the difference in the impact from before and after introducing lignin extraction at a Kraft pulp mill on a systems level. Bernier et al. (2013) also suggest that as the lignin extraction increases the pulp and soap production of the mill, credits for avoiding the production of these in a non-extraction mill could be added. However, as this leads to cascading allocation issues (as discussed earlier, alternative pulp and soap sources are likely also products of multi-output processes) such credits have been excluded from the current study as it has the purpose to illustrate the results of different approaches rather than to describe environmental impacts as correctly as possible. While this can be interpreted as an approach that would be more suitable in consequential LCA studies (focused on seeing how global impacts change as a result of an action), we argue that it can still be used in some attributional LCA studies (focused on seeing what part of the global impacts that should be attributed to each system) if data is gathered with an attributional approach, with the same reasoning as when system expansion by substitution is applied in an attributional study. For a discussion on consequential versus attributional LCAs, see Finnveden et al. (2009). 
Table 1 Allocation procedures used in this study

\begin{tabular}{|c|c|c|}
\hline Allocation method & Description & Reference \\
\hline Changes made to the mill & $\begin{array}{l}\text { Subdivision is simulated in a pragmatic way. Considers only the } \\
\text { impact of the lignin extraction process added to the mill and any } \\
\text { internal energy loss related to lignin removed. }\end{array}$ & Proposed by the authors of this paper \\
\hline Marginal approach & $\begin{array}{l}\text { Considers the difference in impacts of the whole system from before } \\
\text { to after introduction of lignin extraction. }\end{array}$ & Bernier et al. (2013) \\
\hline $\begin{array}{l}\text { Main product bears all } \\
\text { burden }\end{array}$ & $\begin{array}{l}\text { A main product of the system is selected to carry the entire } \\
\text { environmental burden. }\end{array}$ & Sandin et al. (2015) \\
\hline $\begin{array}{l}\text { System expansion by } \\
\text { substitution }\end{array}$ & $\begin{array}{l}\text { The system boundaries are expanded to include the replacement of } \\
\text { other products on the market. }\end{array}$ & $\begin{array}{l}\text { European Commission Joint Research Center } \\
\text { (2010) }\end{array}$ \\
\hline Mass-based allocation & $\begin{array}{l}\text { The impacts of the system are partitioned based on the mass of each } \\
\text { co-product flow. }\end{array}$ & $\begin{array}{l}\text { International Organization of Standardization } \\
\text { (2006) and European Commission Joint } \\
\text { Research Center (2010) }\end{array}$ \\
\hline Energy-based allocation & $\begin{array}{l}\text { The impacts of the system are partitioned based on the energy } \\
\text { content of each co-product flow. }\end{array}$ & $\begin{array}{l}\text { International Organization of Standardization } \\
\text { (2006) and European Commission Joint } \\
\text { Research Center (2010) }\end{array}$ \\
\hline Exergy-based allocation & $\begin{array}{l}\text { The impacts of the system are partitioned based on the exergy } \\
\text { content of each co-product flow. }\end{array}$ & Cherubini et al. (2011) \\
\hline $\begin{array}{l}\text { Energy- and mass-based al- } \\
\text { location }\end{array}$ & $\begin{array}{l}\text { The impacts of the system are first partitioned between energy } \\
\text { streams and material streams based on energy efficiency, followed } \\
\text { by either energy allocation (for energy streams) or mass allocation } \\
\text { (for material streams). }\end{array}$ & Njakou Djomo et al. (2017) \\
\hline $\begin{array}{l}\text { Mass- and energy-based al- } \\
\text { location }\end{array}$ & $\begin{array}{l}\text { The impacts of the system are first partitioned between energy } \\
\text { streams and material streams based on mass conversion rate, } \\
\text { followed by either energy allocation (for energy streams) or mass } \\
\text { allocation (for material streams). }\end{array}$ & Proposed by the authors of this paper \\
\hline Economic allocation & $\begin{array}{l}\text { The impacts of the system are partitioned based on the economic } \\
\text { value of each co-product flow. }\end{array}$ & $\begin{array}{l}\text { International Organization of Standardization } \\
\text { (2006) and European Commission Joint } \\
\text { Research Center (2010) }\end{array}$ \\
\hline $\begin{array}{l}\text { Allocation based on } \\
\text { substituted impacts }\end{array}$ & $\begin{array}{l}\text { The impacts of the system are partitioned based on the impacts of } \\
\text { replaced products. }\end{array}$ & Cherubini et al. (2011) \\
\hline $\begin{array}{l}\text { Allocation based on inversed } \\
\text { substituted impacts }\end{array}$ & $\begin{array}{l}\text { The impacts of the system are partitioned based on the inversed } \\
\text { impacts of replaced products. }\end{array}$ & Sandin et al. (2015) \\
\hline
\end{tabular}

\subsubsection{Main product bears all burden}

Using this approach, a main product of the system is selected and allocated the entire burden of the system. Other products are considered free of burden (Sandin et al. 2015). Applying this method to the system under study under current market conditions for the outputs would make pulp the main product, leaving lignin free of environmental burden. This raises the question of what determines the main product of the system. Arguably, this choice would be based on the reason behind the system's existence and operation, i.e. the driver of the system. While the driver of the studied system currently is the pulp production, in the future or for completely different contexts and technologies, lignin might be the driver and therefore be the main product that should carry the entire burden (see for example the "lignin-first" concept as described by Renders et al. (2017)). In prospective LCA studies that typically look some years into the future, both options could be explored. Note that for systems where there is one of several outputs that is totally dominating in terms of mass, energy, exergy, or price, this approach would give similar results as several other methods described here.

\subsubsection{System expansion by substitution}

Using this approach, the entire environmental burden of the system is allocated to the output represented by the functional unit, and credit is given to the system for avoided impacts related to products that can be assumed to be replaced by the co-products of the system. Information about replaced products and credits applied in this study can be found in Sect. 2.2.4. Although more natural in consequential LCA studies, this approach is commonly applied also in attributional LCA studies and the difference is then what kind of data that is selected.

\subsubsection{Mass-based allocation}

Impacts of the system can be allocated based on physical relationships. One that is commonly used, because it is straightforward, in particular for non-energy products, is mass. 
When using this method, the environmental impact is simply distributed between the different products based on their mass relationship. A higher mass output is allocated a higher environmental burden. A drawback when using this method is that some co-products, such as electricity or heat, do not have a mass and are then not allocated any impact.

As simple and straightforward as it may seem, it has been argued that when ratios between co-products cannot be affected (using the example of rapeseed oil and rapeseed residues), allocation based on physical relationships, e.g. mass, should not be used (Azapagic and Clift 1999). While the ratio between lignin and other components in wood is indeed fixed as in the example above, we argue that how much of the lignin is extracted is limited by process choices rather than the ratio between the lignin and the other wood components (and could in principle be varied) and this method is therefore applicable to the special case of lignin.

\subsubsection{Energy-based allocation}

Another physical relationship that can be used in allocation is energy, dividing impacts between co-products based on their total energy content. While also seeming straightforward and simple, this method has the same drawback as the mass-based allocation approach: some co-products, for example carbon dioxide, do not have an energy value and are consequently not allocated an impact.

\subsubsection{Exergy-based allocation}

An alternative method based on physical relationships is exergy allocation, distributing impacts between outputs based on their exergy content. Cherubini et al. (2011) claim that using exergy as a basis for allocation is beneficial as it can account for both energy and mass flows. Arguments against using exergy as a basis for allocation are that it can be difficult to estimate the exergy content of some flows and that exergy as a concept can be challenging for the public and for policy makers to understand (Cherubini et al. 2011).

\subsubsection{Energy- and mass-based allocation}

As an alternative to using exergy as an allocation basis to be able to account for both material and energy flows, Njakou Djomo et al. (2017) suggest the use of a hybrid energy- and mass-based allocation method. The described rationale behind this method is that as some energy co-products do not have a mass (such as electricity) and some mass co-products (for example carbon dioxide) do not have a heating value, neither mass nor energy allocation are sufficient and a combination of these should therefore be used. Before using the method, it has to be decided which products are to be used for energy purposes and which are to be used for material purposes. A dispatch factor, $\alpha$, is calculated using Eq. (1), in order to split the biorefinery stream into an energy and a material stream that are subsequently dealt with in different ways.

Dispatch factor $\alpha=\frac{\eta_{\text {energy streams }}}{\eta_{\text {energy streams }}+\eta_{\text {material streams }}}$

where $\eta_{\text {energy stream }}$ is the energy efficiency of the energy stream (i.e. energy in energy products out/total energy in) and $\eta_{\text {energy stream }}+\eta_{\text {material stream }}$ is the total energy efficiency of the system (i.e. energy in all products out/total energy in). Allocation factors are then calculated using Eq. (2) for energy products and Eq. (3) for material products.

Allocation factor for energy products

$$
=\alpha * \frac{\text { Energy content product }_{i}}{\text { Total energy }}
$$

Allocation factor for mass products ${ }_{j}$

$$
=(1-\alpha) * \frac{\text { Mass of } \text { product }_{j}}{\text { Total mass }}
$$

where Total energy represents the energy content of all energy streams and Total mass the mass of all material streams.

A drawback when using this method is that in one extreme case where there is no energy content at all in the material flows (for example when generating carbon dioxide and ashes that will be used for material purposes), the dispatch factor is calculated to be 1 , initially allocating all impacts to the energy streams. This leads to material co-products not getting any impact as the dispatch factor is based on energy content. An alternative would be to base the first partitioning on mass, which is described in Sect. 2.1.9, but that would introduce the same drawback vis-à-vis energy co-products without mass that will end up with no impact. Further, it can be difficult to identify which products are to be used for energy purposes and which are to be used for material purposes. In this paper, we explore two cases: one where lignin is considered to be a polymer or chemical precursor and one where lignin is considered to be an energy source or fuel precursor.

\subsubsection{Mass- and energy-based allocation}

This method is an alternative to the one suggested by Njakou Djomo et al. (2017), and instead of basing the dispatch factor on the energy efficiency, we propose that it can be based on the mass conversion rate. This allows for dealing with allocation in systems with large mass outputs without energy content. The dispatch factor, $\beta$, is calculated using Eq. (4).

$$
\text { Dispatch factor } \beta=\frac{\eta_{\text {material streams }}}{\eta_{\text {mass in energy streams }}+\eta_{\text {mass in material streams }}}
$$


where $\eta_{\text {material stream }}$ (i.e. mass in material purpose products out/total mass in) and $\eta_{\text {mass in energy stream }}+\eta_{\text {mass in material stream }}$ is total material conversion rate of the system (i.e. mass in all products out/total mass in). Allocation factors are then calculated using Eq. (5) for material products and Eq. (6) for energy products:

Allocation factor for mass products ${ }_{j}=\beta * \frac{{\text { Mass of } \text { product }_{j}}_{\text {Total mass }}}{\text { Tol }}$

Allocation factor for energy products ${ }_{i}$

$$
=(1-\beta) * \frac{\text { Energy content product }_{i}}{\text { Total energy }}
$$

where Total mass represents the mass of all material purpose streams and Total energy the energy content of all energy purpose streams. While the drawbacks of using this method are the same as for the original energy- and mass-based allocation method, it shows the impact of an alternative allocation basis, and it better represents systems with a large mass output without energy content.

\subsubsection{Economic allocation}

The rationale behind this allocation approach is that the economic value of the products is the driver of the system, i.e. the reason that the system exists and is operated (Huppes and Schneider 1994). In this study, we apply two different lignin prices as a basis for allocation: $0.3 € / \mathrm{kg}$, representing today's situation (González-García et al. 2016), and a ten-fold increase of today's price because of an increased demand for high quality lignin (i.e. $3 € / \mathrm{kg}$ lignin). As lignin is today often considered a waste or an internal fuel and therefore has a price reflecting this (from zero to the cost of an alternative fuel), a future decrease in price is not anticipated and therefore not assessed. Assuming a very low price of lignin would be similar to seeing the pulp as the main product, as described in Sect. 2.1.3. Prices for other co-products are, for simplicity, held constant over time, see Supplementary Material.

\subsubsection{Allocation based on substituted impacts}

Cherubini et al. (2011) suggest a hybrid approach to allocation where environmental impacts are allocated among coproducts using the environmental impact of the products they could replace as an allocation basis. The rationale behind this method is that it is the combined system of existing products and functions that would be replaced by the system with lignin extraction that should determine how burdens are allocated. It can be seen as a rescaling of the total impacts of the system based on the reference system, as a consequence also avoiding ascribing negative impact results to any of the co-products as can very well happen in system expansion by substitution. The calculation of allocation factors is described in Eq. (7):

Allocation factor $i=\frac{u_{i} * y_{i}}{\sum_{i=1}^{n} u_{i} * y_{i}}$

where $u_{i}$ is the life cycle impact of the replaced product $i, y_{i}$ is the flow of that product, and $\sum_{i=1}^{n} u_{i} *_{i}$ represents the total avoided environmental impact from delivering $\mathrm{n}$ functions.

\subsubsection{Allocation based on inversed substituted impacts}

Sandin et al. (2015) suggests a variant of the method proposed by Cherubini et al. (2011) that inverts the environmental burden of the avoided products. They argue that the original method seems to contradict the idea that avoiding production (and, as a consequence, impacts) is desirable. The product that can prevent the largest environmental burden should therefore be given the best environmental profile. The calculation of allocation factors is described in Eq. (8):

Allocation factor $i=\frac{1-\frac{u_{\mathrm{i}} * y_{i}}{\sum_{i=1}^{n} u_{i} * y_{i}}}{n-1}$

The substituted products are assumed to be the same as for the allocation based on substituted impacts approach (see Sect. 2.1.11) and are found in Table 2.

\subsection{Case study}

The case study used to apply the allocation methods is lignin extraction from a Kraft pulp mill located in Sweden. The Kraft pulp mill was chosen because of data availability (data on other pulp mills and biorefineries are scarce, especially when including lignin extraction), because Kraft pulp mills are wellestablished and because there is a known method for extraction of lignin at such mills. Sweden as a location was chosen as we wanted a European setting for the study and Sweden has a relatively large forestry industry and presence and long history of Kraft pulp mills.

\subsubsection{Functional unit and system boundaries}

The functional unit of this study is $1 \mathrm{~kg}$ of extracted lignin from a Kraft pulp mill in Sweden. The system boundaries are cradle-to-gate and any post-treatment of the lignin that might be needed for the intended application is not taken into account.

\subsubsection{System description}

Figure 1 describes the modeled system, which is based on Culbertson et al. (2016), Hamaguchi et al. (2012), and 
Table 2 Replaced products and the credits used in system expansion by substitution, allocation based on substituted impacts, and allocation based on inversed substituted impacts

\begin{tabular}{|c|c|c|c|c|}
\hline & Replaced product & $\begin{array}{l}\text { Avoided impacts per } \\
\mathrm{kg} \text { of replaced product } \\
\text { (kg CO} / 2 \text { or per } \\
\text { MWh replaced product) }\end{array}$ & $\begin{array}{l}\text { Avoided impacts per } \\
\mathrm{kg} \text { functional unit } \\
\left(\mathrm{kg} \mathrm{CO}_{2} / \mathrm{kg} \text { lignin }\right)\end{array}$ & Reference \\
\hline Pulp (kg): Alternative 1 & Cotton & 2.9 & 27 & Ecoinvent 3.3 \\
\hline Pulp (kg): Alternative 2 & $\begin{array}{l}\text { Reading a magazine } \\
\text { on a tablet }\end{array}$ & 0.35 & 3.2 & $\begin{array}{l}\text { Based on estimations from characterized } \\
\text { results from Ahmadi Achachlouei et al. } \\
\text { (2015) and Achachlouei and Moberg (2015) }\end{array}$ \\
\hline $\begin{array}{l}\text { Lignin }(\mathrm{kg}) \text { : Used as a } \\
\text { material product }\end{array}$ & PAN & 0.56 & $\mathrm{n} / \mathrm{a}$ & $\begin{array}{l}\text { European Platform on Life Cycle } \\
\text { Assessment (2018) }\end{array}$ \\
\hline $\begin{array}{l}\text { Lignin }(\mathrm{kg}) \text { : Used as a } \\
\quad \text { fuel precursor }\end{array}$ & Crude petroleum & 0.24 & $\mathrm{n} / \mathrm{a}$ & Ecoinvent 3.3 \\
\hline Soap $(\mathrm{kg})$ & Crude petroleum & 0.24 & 0.063 & Ecoinvent 3.3 \\
\hline Heat (MWh) & District heating & 58 & 0.67 & Werner (2017) \\
\hline
\end{tabular}

Staffas et al. (2013). The co-products from the process are pulp, soap, heat, and lignin.

Lignin can be extracted from the black liquor in the Kraft pulping process using a process called LignoBoost. The black liquor (consisting of cooking chemicals and organic compounds from the wood, such as lignin) is led from the evaporator in the Kraft pulp mill into the LignoBoost process. The LignoBoost process includes acidification of the black liquor with $\mathrm{CO}_{2}$ for precipitation of the lignin, followed by filtration and dewatering, which is done in two cycles. After the lignin is extracted, the filtrate is sent back to the evaporator (Tomani 2010). The extraction of lignin from the black liquor does not only generate another product that can be sold to bring revenue to the mill, it also increases the production of pulp for a constant load of the recovery boiler, which is often the bottleneck of the mill (Axelsson et al. 2006). In the system described by Culbertson et al. (2016), such a debottlenecking leads to an increased production of both pulp and soap. The heat output of the mill is, however, lower when extracting lignin.

Inventory data for the Kraft pulping process (with and without lignin extraction) were based on the data provided by Culbertson et al. (2016). For the present study, data from a scenario where lignin extraction leads to an increased production at the pulp mill were used (referred to as "Lignin Extraction Operation \& Pulp Mill at Recovery Boiler Solids Limited Capacity"). The dataset was adapted for the present study to better fit Swedish conditions as the mill was originally set in Southeast USA. The adaptation includes exchanging the original natural gas input for an approximation of the energy mix used by the pulping industry in Sweden. The Swedish pulping industry uses energy generated from biomass $(70 \%)$ and electricity (27\%) and the rest is unknown (3\%, excluded in our study) (The Swedish Energy Agency 2017). For this study, the Ecoinvent 3.3 APOS database
(Wernet et al. 2016) was used if not stated otherwise. Finally, all transports have been excluded as these are uncertain, vary from case to case, and are assumed to be negligible and unimportant in this context.

In the allocation method changes made to the mill (see Sect. 2.1.1 and Table 1), inventory data for the lignin extraction process and the energy lost with the extracted lignin are needed. However, based on the data provided by Culbertson et al. (2016), the impact from the LignoBoost process cannot be separated in a well-defined way from the entire Kraft mill impact. Therefore, a dataset for only the LignoBoost process by Benali et al. (2016) was used. The dataset was adapted to Swedish conditions, in the same way as the dataset by Culbertson et al. (2016) and when ranges were reported, the average values were used. Energy from an external source to compensate for the energy loss related to the extracted lignin was assumed to be the same as used in the Kraft pulp mill, i.e. the energy mix used in the pulping industry in Sweden.

\subsubsection{Impact assessment method}

Due to limited data availability, only climate impact is considered in this study. This was deemed sufficient given the purpose of the study. As climate impact often correlates well with other impacts, it can also function as a proxy for other impacts (Janssen et al. 2016). The impact assessment method used for the lignin production was GWP100 by IPCC 2007 as provided by Ecoinvent 3.3 (Wernet et al. 2016). In this method, biogenic $\mathrm{CO}_{2}$ and $\mathrm{CO}$ do not have characterization factors.

\subsubsection{Substitution credits}

Selecting products to substitute can be a difficult task and has to be strongly aligned with the goal and scope of the study. In this case study, the produced pulp is assumed to replace an 
Fig. 1 The flow diagram of the Kraft process with LignoBoost lignin extraction that is considered in this paper (Culbertson et al. 2016; Hamaguchi et al. 2012; Staffas et al. 2013)

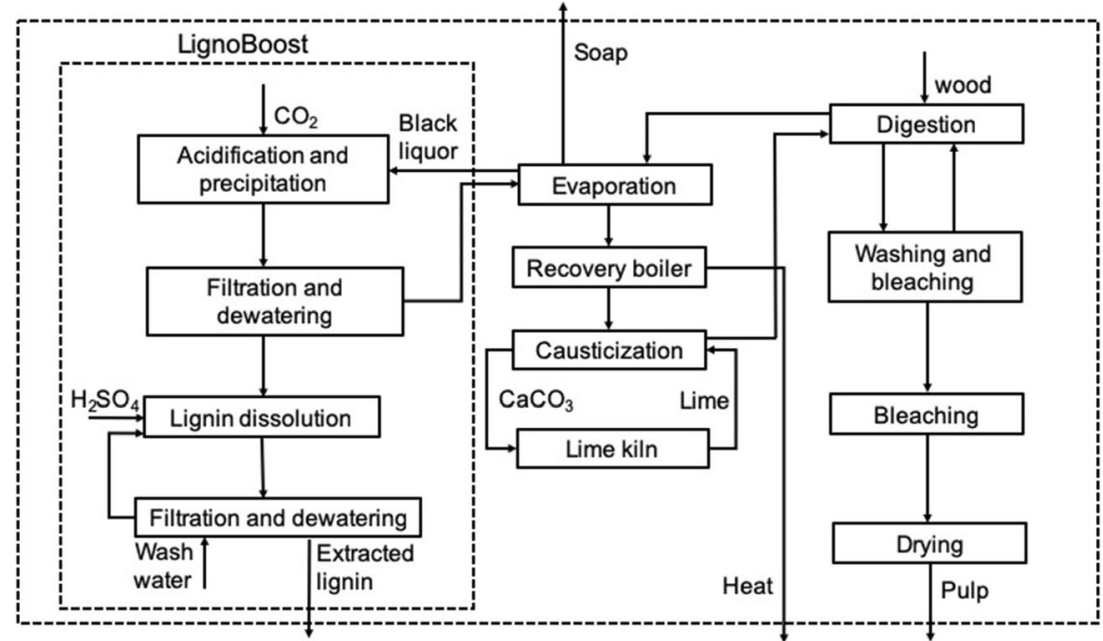

equivalent amount of cotton fiber in sanitary products (as fluff) or the reading of a magazine on a tablet. The latter was suggested as a reference product (or "avoided product") by Sandin et al. (2015) and was therefore selected here but in a consequential context, this might not be a good assumption as it would likely be the other way around, i.e. that reading a magazine on a tablet would replace reading on paper, given current global trends. Given the purpose of the case study is to test the practical applicability of allocation methods and explore the range of results, it was deemed useful in this context. Data were lacking for the further treatment of pulp for use in magazine paper, and this step was therefore excluded. The substitution credit therefore represents a more complete system than the pulp output from our system and the gain is therefore overestimated. The soap leaving the Kraft pulp mill is assumed to be further treated into tall oil and finally into biodiesel (this was included in the substituted system), and then substituting the same amount of crude petroleum (assuming an exchange rate of 1:1 between soap and crude petroleum). Finally, the heat output of the mill is assumed to replace district heating (with an impact approximated using data from Werner (2017)). The resulting credits for these products can be found in Table 2 .

In the methods allocation based on substituted impacts (see Sect. 2.1.11) and allocation based on inversed substituted impacts (see Sect. 2.1.12), lignin is assumed to replace either a polymer precursor or a fuel precursor, see Table 2. Replaced products are assumed to be polyacrylonitrile (PAN), which is the main material used for producing carbon fibers today (approximated by PAN precursor fiber), and crude petroleum (when extracted lignin is seen as a fuel precursor), respectively.

\subsection{Potential lignin applications}

While there are many potential applications for lignin, we chose (primarily based on data availability) to look into a comparison with the following technologies: PAN for the production of carbon fibers that are subsequently used in CFRP (Das 2011), fossil phenol for the production of tert-butyl catechols (TBC) (Montazeri and Eckelman 2016), and ureaformaldehyde for medium density fiberboards (MDF boards) (Piekarski et al. 2017). When producing carbon fibers from lignin, the yield is assumed to be $50 \%$ (i.e. $2 \mathrm{~kg}$ of lignin is needed for producing $1 \mathrm{~kg}$ of carbon fiber). For the production of TBC, $3 \mathrm{~kg}$ of lignin is assumed to be needed to produce enough to replace the fossil raw material needed for the production of $1 \mathrm{~kg}$ of TBC (this assumption is based on calculations using data from Montazeri and Eckelman (2016); for more information, see the Supplementary Material). When replacing urea-formaldehyde, it was assumed that $1 \mathrm{~kg}$ of lignin replaces $1 \mathrm{~kg}$ of urea-formaldehyde.

In all cases, the climate impact of the lignin needed to replace a substance or material as mentioned above was calculated by multiplying the impact of $1 \mathrm{~kg}$ of lignin with the amount of lignin needed in each application as stated above (note that the impact of lignin can be negative, depending on which allocation method is used for the lignin production). Finally, the normalized climate impact of lignin in each application was calculated using Eq. 9.

Normalized climate impact

$$
=\frac{\text { Climate impact of lignin needed in application }}{\text { Climate impact of application }}
$$

\section{Results and discussion}

\subsection{The climate impact of lignin}

Figure 2 shows the climate impact for the production of $1 \mathrm{~kg}$ of lignin using the different allocation approaches and their variants. 


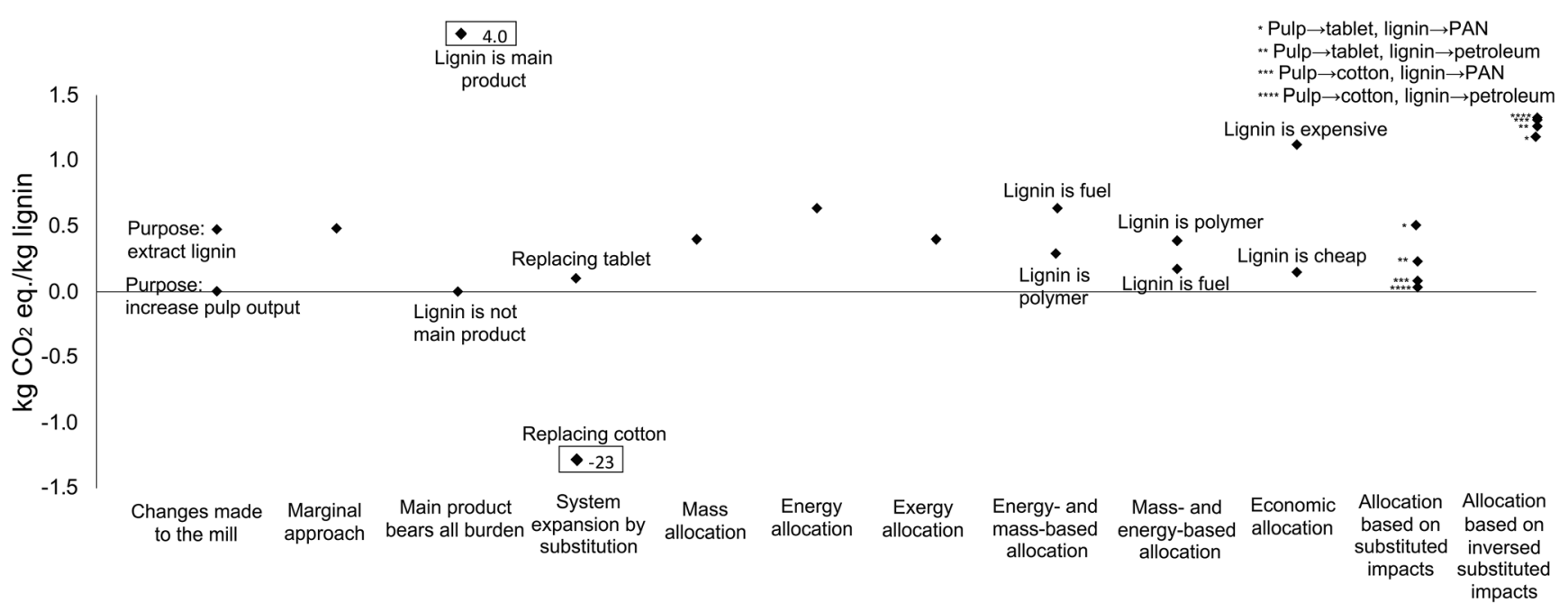

Fig. 2 The climate impact of $1 \mathrm{~kg}$ of lignin using different allocation methods. The numbers in boxes are for outliers that do not fit on the $y$-axis scale

The results show that the climate impact of lignin varies significantly depending on the choice of allocation method: System expansion by substitution exhibits a climate impact close to zero when replacing reading a magazine on a tablet and a negative climate impact, in fact, the lowest of all applied methods, when pulp is replacing cotton. Assuming lignin as the main product of the system results, not surprisingly, in the highest climate impact.

The results from applying the method main product bears all burden is highly sensitive to which product is seen as the driver of the system. In a system where pulp is considered the main product (i.e. the typical situation today), lignin is free of impact. In a possible future where the demand for lignin has increased and different lignin extraction technologies exist at a large scale, lignin might be seen as the main product, bearing all burden of the system using this approach, resulting in an impact as high as $4.0 \mathrm{~kg} \mathrm{CO}$ eq. $/ \mathrm{kg}$ lignin. The same phenomenon, however not as obvious as this only considers the lignin extraction and not the whole system, is also present in the approach changes made to the mill. Here, the driver for extracting the lignin is of importance: When lignin is extracted to increase the pulp output, the lignin is considered free of burden as the impact from the lignin extraction is allocated to the pulp. If the lignin is extracted with the purpose of selling the lignin as a stand-alone product, the impact of lignin extraction is allocated to the lignin, resulting in an impact of $0.47 \mathrm{~kg} \mathrm{CO}_{2}$ eq. $/ \mathrm{kg}$ lignin. Since the driver behind the introduction of the extraction determines the outcome in these approaches, this needs to be carefully considered, especially as this may change in the future. It is, however, sometimes difficult to determine what is the main reason for the extraction or if there is a mixed purpose. One way of addressing mixed drivers is suggested by Svanström et al. (2017). They developed a two-stage Delphi procedure (a technique for obtaining consensus in the opinion of an expert panel, based on the work by Dalkey and Helmer (1963)) to find allocation factors for use in attributional LCAs where multiple drivers are present. The method was employed for a wastewater and sludge management system and the resulting allocation factors were shown to potentially have a large influence on the results. One possible point of critique against the changes made to the mill approach is that it does not reevaluate what the driver is for operating different parts of the system after the lignin extraction has been introduced. It is based on the assumption that lignin was a waste or a by-product of very low value that is now better utilized. The marginal approach exhibits impact very similar to changes made to the mill $\left(0.48 \mathrm{~kg} \mathrm{CO}_{2}\right.$ eq. $/ \mathrm{kg}$ lignin), which was expected as the basic rationale behind these two approaches is similar. Note, however, that credits for the avoided impacts related to increased production of pulp and soap for both methods were excluded due to cascading allocation issues.

In the system expansion by substitution approach, letting pulp replace cotton results in a significantly lower climate impact ( $-23 \mathrm{~kg} \mathrm{CO}$ eq. $/ \mathrm{kg}$ lignin) than replacing reading a magazine on a tablet $(0.091 \mathrm{~kg} \mathrm{CO}$ eq. $/ \mathrm{kg}$ lignin), and the difference would be even larger if the processing of the pulp into magazine grade paper had been included. The large credit related to cotton is due to the use of electricity throughout the cradle-to-gate production process (e.g. irrigation, harvesting, etc.), but this impact is heavily dependent on the location of activities and temporal boundaries, in this case the USA during the late 2000s.

The five allocation methods that are based on physical relationships (mass-based allocation, energy-based allocation, exergy-based allocation, energy- and mass-based allocation, and mass- and energy-based allocation) all lead to results in the same order of magnitude $\left(0.18-0.64 \mathrm{~kg} \mathrm{CO}_{2}\right.$ eq./kg lignin, see Fig. 2), with energy based allocation, exergy-based allocation, and energy-and mass-based 
allocation for lignin used as an energy source showing a slightly higher climate impact than mass-based allocation. This is because of the high exergy and energy content of lignin compared with the pulp (this difference is however evened out to some extent by the large mass output of pulp compared to lignin). Applying energy-and mass-based allocation to a system where lignin is assumed to be a non-energy product, such as a polymer or a precursor for chemicals, results in a lower climate impact. This is because the relative mass output of lignin is small in relation to the mass output of pulp. This can be compared to the relatively high energy output of lignin (when considered a fuel precursor) in relation to soap and lignin. This results in a higher allocation factor for lignin when it is considered to be a fuel and a lower when it is considered to be a material. Using the mass-and energy-based allocation method when lignin is considered a material results in practically the same climate impact as when using a classic massallocation approach (in this case, the dispatch factor $\beta$ is calculated to be very close to 1 , meaning that in practice, a classical mass allocation is done for lignin as almost all impacts are allocated to the material streams, in this case pulp and lignin). When considering lignin to be a fuel, the climate impact is lower as the impacts are divided between the material streams and the energy streams. The need of determining what products are used for energy purposes and what are used for material purposes might however be problematic as the end application is not always known at the mill or biorefinery and different scenarios might therefore be warranted.

Figure 2 also shows that the price of lignin has a great influence on the resulting climate impact (the resulting impact ranging from $0.15 \mathrm{~kg} \mathrm{CO}$ eq. $/ \mathrm{kg}$ lignin when lignin is cheap to $1.1 \mathrm{~kg} \mathrm{CO}_{2}$ eq. $/ \mathrm{kg}$ lignin when lignin is expensive) and that the environmental impact of lignin production in the future, using economic allocation, might be higher than the impact today if prices increase. These results are based on the assumption that the prices of the other co-products of the system remain unchanged, which is not necessarily true. For example, the price of pulp could remain the same because it is a mature technology with a stable market, but the price could also decrease due to a lower demand. For soap, there is the same uncertainty as for lignin; the market for bio-diesel might grow resulting in a higher price, but this is hard to predict. All of the suggested effects on the prices would result in changes for the allocation factors and, as a consequence, the climate impact of lignin. As it is difficult to predict future market prices, in particular for emerging technologies, results from using this allocation method are uncertain, and different scenarios might be required.

Finally, two versions of the allocation based on substituted impacts approach were tested. The original method suggested by Cherubini et al. (2011) results in a climate impact between $0.036-0.50 \mathrm{~kg} \mathrm{CO}_{2} / \mathrm{kg}$ lignin (lowest for pulp replacing cotton and lignin replacing petroleum and highest for pulp replacing reading on a tablet and lignin replacing PAN), while the altered version (i.e. inversed) suggested by Sandin et al. (2015) results in a higher impact of around $1.2-1.3 \mathrm{~kg} \mathrm{CO}_{2}$ eq. $/ \mathrm{kg}$ lignin, where the lowest value is for pulp replacing a tablet and lignin replacing PAN and the highest for pulp replacing cotton and lignin replacing petroleum. The small variation in resulting environmental impact between variants in each method indicates that they are in our case not as sensitive to the choice of replaced products as in system expansion by substitution. This is because of the rescaling effect earlier mentioned. When substituted systems in reality have a large impact, this approach scales these impacts down. Had the substituted systems had a low impact, this approach would scale up the importance of each of the subsystems. The allocation based on inversed substituted impacts approach instead makes an inversed rescaling and allocates the lowest share of environmental burden to the product avoiding the lowest impact. The recommendation by Sandin et al. (2015) is to use this method as a complement to more traditional methods in a sensitivity analysis as it is still rather new and untested, i.e. the potential implications are still poorly understood. The difference in resulting impacts (in our case large when using system expansion by substitution and small when rescaling as in allocation based on substituted impacts or allocation based on inversed substituted impacts) raises the question: What choices regarding substitution are important and what guidance can be provided? Choosing reading on a tablet as the product being replaced by pulp in this paper could be questioned. It is, as earlier mentioned, unlikely that an increased output of pulp would reduce the reading on a tablet. However, it is used here to illustrate the importance of the choice of reference product. Another possible use of pulp is in bio-composites for packaging purposes, partially replacing a share of plastic component while still maintaining the function; see Hermansson et al. (2016) for an environmental assessment of such a product, a mixture of pulp and polylactic acid. However, since this material is not yet generated in large scale and also involves multi-output processes, we have left it out from this assessment.

The variation in results presented in Fig. 2 is not only because of different allocation approaches but also because of different assumptions made within the different approaches. These are all related to three main factors: (1) market and price of different outputs; (2) what is seen as the main product or the driver of the system or system changes; (3) what the surrounding system looks like and hence what other products will be displaced by outputs. All of these are important to look into in LCAs of multi-output processes but can be particularly challenging in prospective studies as such studies are future-oriented and consider systems that do not yet exist. The first two factors highlight the importance of understanding the market and determining the driver of the system or system change and how these might develop over time. 
Industrial processes are often, but not always, commercially driven and dependent on a market for the outputs (see Svanström et al. (2017) for a discussion on systems in wastewater management that are not commercially driven). What is seen as the main product of the system now and in a plausible future and the output that is the reason that changes are made to the system now and in a plausible future can be different and timeframes can be critical to establish. When assessing products from multi-output systems with emerging markets, how the market develops can be important, but also how the technology itself develops, for example in terms of technology maturity or use of raw materials. Another possibly important factor could also be whether parts of the production plant already existed or if new parts are being introduced to extract new products. Finally, it is also important to carefully assessing the surrounding systems and how these might change. Changes in surrounding systems can lead to other products being replaced than today, but the replaced products could also come with a different environmental profile, e.g. related to the electricity mix used in their production.

It should be noted that production capital has not been considered in the present study, even when changes are considered to be made to a process or when a not yet existing process is assessed. This is a common assumption in LCA and is often a valid simplification for processes with long lifetime and/or a large throughput of energy and materials. Such a choice also depends on the goal and scope of a study. If included, the production capital may also have to be allocated between outputs, and it is reasonable to consider e.g. the driver behind the construction of the process in such assessments.

If the variants of the allocation methods in Fig. 2 that represent a future where the importance of lignin has increased (and is therefore seen as a main output with high economic value) are considered, the resulting environmental impact of the lignin typically increases. The choice of allocation approach and the choices within an approach will therefore likely be increasingly important in the future as it can be expected that the importance of lignin outputs increases. Different allocation scenarios could be explored to capture important uncertainties and sensitivities in LCA of lignin or of other emerging technologies involving multiple outputs.

\subsection{Lignin's possible influence on the climate impact of products}

To shed light on to what extent the levels and ranges of impacts of lignin reported in Fig. 2 are critical when seen in the context of full life cycles, a comparison to LCA results available in the literature for some traditional products that emerging lignin-based technologies could compete with was made

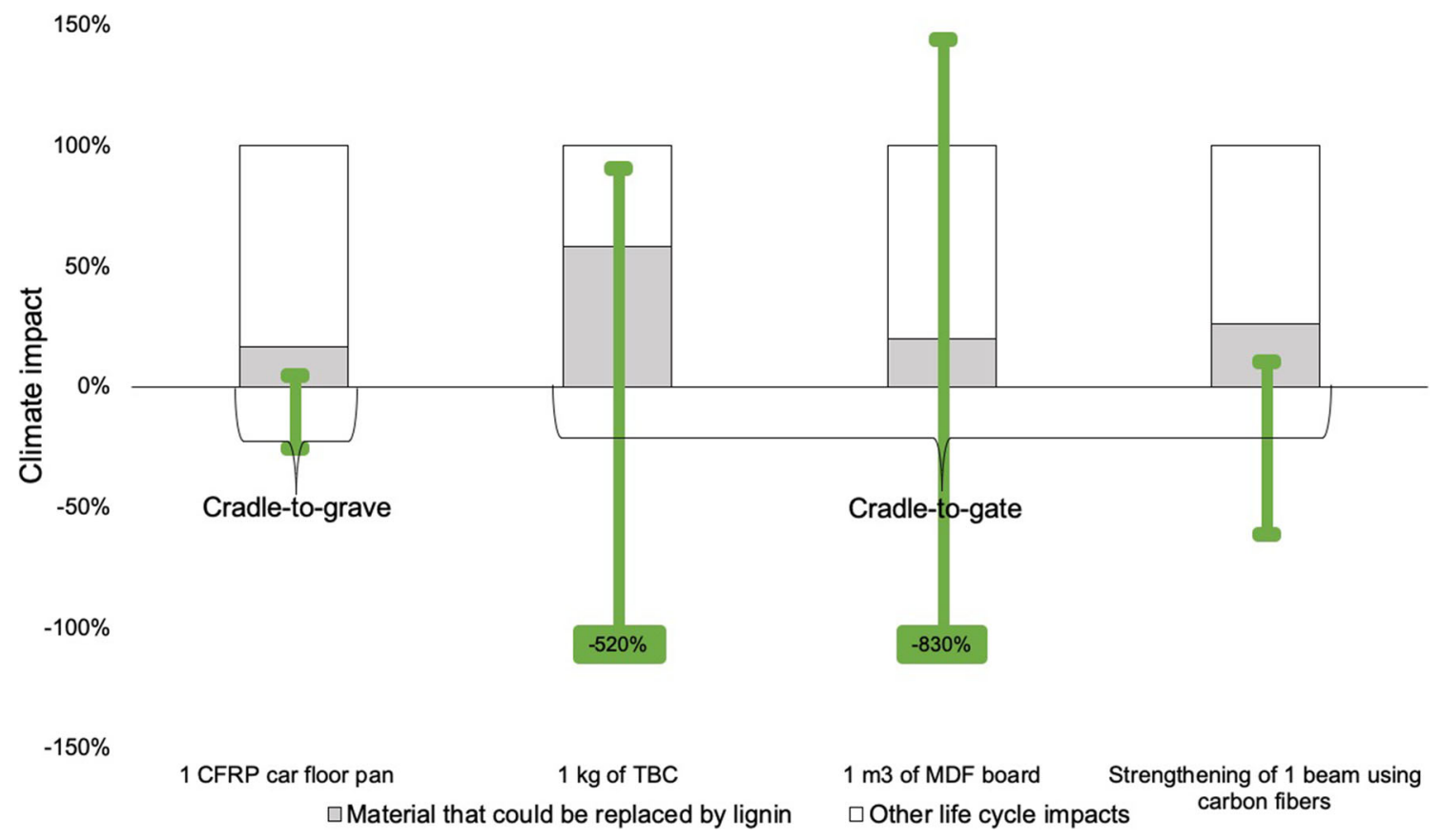

Fig. 3 Illustration of the influence of the choice of allocation method for lignin production on comparisons to four alternative products, all normalized to $100 \%$ : (1) a light-weight car floor pan where lignin could replace PAN as a precursor material for the carbon fibers in the composite (Das 2011), (2) as an alternative to phenol in TBC (Montazeri and Eckelman (2016)), (3) replacing urea-formaldehyde in MDF boards (Piekarski et al. (2017)), and (4) replacing PAN as a carbon fiber precursor material in composites for strengthening of construction beams (using average data from Maxineasa et al. (2015)). The allocation-dependent variability of the lignin production impact is represented by the length of the green whiskers. These should be compared with the gray parts of the bars, which represent the material or chemical that lignin would substitute. The white parts of the bars represent other parts of the life cycles. The green boxes represent outliers that could not fit on the $y$-axis using the selected scale 
(see Sect. 2.3 for a description of these). The intention here is not to suggest where a replacement by lignin could make the largest difference but to illustrate if and how the choice of allocation approach could have a large influence on the results of such a comparison.

The two carbon fiber cases presented in Fig. 3 include impacts related to carbon fiber processing such as spinning, stabilization, and carbonization, which was not included for lignin, which means that the impact of the PAN raw material in reality is lower than illustrated in Fig. 3. In the same way, impacts of phenol used in TBC production and ureaformaldehyde in MDF boards also include some impacts related to processing, which are not included for the lignin. None of the lignin cases include any post-treatment of the lignin (such as drying or purification) that would in reality be needed for the intended application. In spite of these uncertainties and inconsistencies, it is evident that the choice of allocation approach may have a significant influence on the final climate impact of a lignin-based alternative of any of the applications shown. It should be noted that only the comparison with a CFRP car floor pan involves a full cradle-to-grave life cycle (see the bar furthest to the left in Fig. 3). This means that the significance of lignin is exaggerated in the other three cases compared with the first comparison. However, it is safe to say that the importance of using a relevant allocation approach (or several) is high.

\section{Conclusions}

Lignin, a co-product from biorefineries and pulp mills, is a material that is gaining more and more attention as a possible future renewable material in a large variety of different applications. We show in this paper that the life cycle climate impact that lignin will contribute to any such application depends strongly on the allocation method applied to the multioutput process that generates the lignin output. Important factors in allocation are related to potential changes in prices and markets, in the surrounding system (i.e. what products will be replaced by lignin and other co-products of the system) and in what is seen as the main product or the driver of the system or any changes made to the system, for example identifying the purpose of extracting the lignin from the pulp mill. These factors are all sensitive to temporal boundaries and should all be considered in LCA of emerging technologies involving multi-output processes.

Acknowledgements Open access funding provided by Chalmers University of Technology.

Funding information This project has received funding from the Bio Based Industries Joint Undertaking under the European Union's Horizon 2020 research and innovation programme under grant agreement No 720707.

\section{References}

Achachlouei MA, Moberg Å (2015) Life cycle assessment of a magazine, part II: a comparison of print and tablet editions. J Ind Ecol 19:590 606. https://doi.org/10.1111/jiec.12229

Ahmadi Achachlouei M, Moberg Å, Hochschorner E (2015) Life cycle assessment of a magazine, part I: tablet edition in emerging and mature states. J Ind Ecol 19:575-589. https://doi.org/10.1111/jiec. 12227

Arvidsson R, Tillman AM, Sandén BA, Janssen M, Nordelöf A, Kushnir D, Molander S (2018) Environmental assessment of emerging technologies: recommendations for prospective LCA. J Ind Ecol 22: 1286-1294. https://doi.org/10.1111/jiec.12690

Axelsson E, Olsson MR, Berntsson T (2006) Increased capacity in kraft pulp mills: lignin separation and reduced steam demand compared with recovery boiler upgrade. Nord Pulp Pap Res J 21:485-492. https://doi.org/10.3183/npprj-2006-21-04-p485-492

Azapagic A, Clift R (1999) Allocation of environmental burdens in multiple-function systems. J Clean Prod 7:101-119. https://doi. org/10.1016/S0959-6526(98)00046-8

Benali M, Ajao O, Jeaidi J, Gilani B, Mansoornejad B (2016) Integrated lignin-Kraft pulp biorefinery for the production of lignin and its derivatives: economic assessment and LCA-based environmental footprint. In: Production of Biofuels and Chemicals from Lignin. Springer, pp 379-418. https://doi.org/10.1007/978-981-10-19654_13

Bernier E, Lavigne C, Robidoux PY (2013) Life cycle assessment of kraft lignin for polymer applications. Int J Life Cycle Assess 18:520-528. https://doi.org/10.1007/s11367-012-0503-y

Cherubini F, Strømman AH, Ulgiati S (2011) Influence of allocation methods on the environmental performance of biorefinery products - a case study. Resour Conserv Recy 55:1070-1077. https://doi.org/10.1016/j.resconrec.2011.06.001

Culbertson C, Treasure T, Venditti R, Jameel H, Gonzalez R (2016) Life Cycle Assessment of lignin extraction in a softwood kraft pulp mill. Nord Pulp Pap Res J 31:30-U247. https://doi.org/10.3183/npprj2016-31-01-p030-040

Dalkey N, Helmer O (1963) An experimental application of the Delphi method to the use of experts. Management Science 9:458-467. https://doi.org/10.1287/mnsc.9.3.458

Das S (2011) Life cycle assessment of carbon fiber-reinforced polymer composites. Int J Life Cycle Assess 16:268-282. https://doi.org/10. 1007/s11367-011-0264-z

Ekvall T, Finnveden G (2001) Allocation in ISO 14041 - a critical review. J Clean Prod 9:197-208. https://doi.org/10.1016/S09596526(00)00052-4

European Commission Joint Research Center (2010) ILCD handbookgeneral guide for life cycle assessment-detailed guidance vol 10 . Joint Research Center - European Commission Luxem bourg Publications Office of the European Union. https://doi.org/10. $2788 / 38479$

European Platform on Life Cycle Assessment (2018) ELCD. Retrieved from: https://eplca.jrc.ec.europa.eu/ELCD3/index.xhtml

Finnveden G et al (2009) Recent developments in life cycle assessment. J Environ Manage 91:1-21. https://doi.org/10.1016/j.jenvman.2009. 06.018

González-García S, Gullón B, Rivas S, Feijoo G, Moreira MT (2016) Environmental performance of biomass refining into high-added value compounds. J Clean Prod 120:170-180. https://doi.org/10. 1016/j.jclepro.2016.02.015

GreenLight (2016) GreenLight-cost effective lignin-based carbon fibres for innovative light-weight applications. https://greenlight-project. eu. Accessed 9th of december 2018 
Hamaguchi M, Cardoso M, Vakkilainen E (2012) Alternative technologies for biofuels production in kraft pulp mills - potential and prospects. Energies 5:2288-2309. https://doi.org/10.3390/en5072288

Hermansson F, Janssen M, Gellerstedt F (2016) Environmental evaluation of Durapulp Bio-composite using LCA: comparison of two applications. J For 5:68-76

Hermansson F, Janssen M, Svanström M (2019) Prospective study of lignin-based and recycled carbon fibers in composites through meta-analysis of life cycle assessments. J Clean Prod 223:946956. https://doi.org/10.1016/j.jclepro.2019.03.022

Huppes G, Schneider F (1994) Proceedings of the European Workshop on Allocation in LCA: at the Centre of Environmental Science of Leiden University, Section Substances \& Products, Leiden, 24th and 25th of February 1994. CML-S \& P

International Organization of Standardization (2006) Environmental management-life cycle assessment-principles and framework (ISO 14040)

Janssen M, Xiros C, Tillman A-M (2016) Life cycle impacts of ethanol production from spruce wood chips under high-gravity conditions. Biotechnol Biofuels 9:53. https://doi.org/10.1186/s13068-0160468-3

LIBRE (2016) LIBRE-lignin based carbon fibres for composites. http:// libre2020.eu. Accessed 9:th of November 2018

Maxineasa SG, Taranu N, Bejan L, Isopescu D, Banu OM (2015) Environmental impact of carbon fibre-reinforced polymer flexural strengthening solutions of reinforced concrete beams. Int J Life Cycle Assess 20:1343-1358. https://doi.org/10.1007/s11367-0150940-5

Modahl IS, Brekke A, Valente C (2015) Environmental assessment of chemical products from a Norwegian biorefinery. J Clean Prod 94: 247-259. https://doi.org/10.1016/j.jclepro.2015.01.054

Montazeri M, Eckelman MJ (2016) Life cycle assessment of catechols from lignin depolymerization. ACS Sustain Chem Eng 4:708-718. https://doi.org/10.1021/acssuschemeng.5b00550

Njakou Djomo S et al (2017) Solving the multifunctionality dilemma in biorefineries with a novel hybrid mass-energy allocation method. Gcb Bioenergy 9:1674-1686. https://doi.org/10.1111/gcbb.12461

Piekarski CM, de Francisco AC, da Luz LM, Kovaleski JL, Silva DAL (2017) Life cycle assessment of medium-density fiberboard (MDF) manufacturing process in Brazil. Sci Total Environ 575:103-111. https://doi.org/10.1016/j.scitotenv.2016.10.007
Ragauskas AJ, Beckham GT, Biddy MJ, Chandra R, Chen F, Davis MF, Davison BH, Dixon RA, Gilna P, Keller M, Langan P, Naskar AK, Saddler JN, Tschaplinski TJ, Tuskan GA, Wyman CE (2014) Lignin valorization: improving lignin processing in the biorefinery. Science 344:1246843. https://doi.org/10.1126/science.1246843

Renders T, Van den Bosch S, Koelewijn S-F, Schutyser W, Sels B (2017) Lignin-first biomass fractionation: the advent of active stabilisation strategies. Energ Environ Sci 10:1551-1557. https://doi.org/10. 1039/C7EE01298E

Sandin G, Røyne F, Berlin J, Peters GM, Svanström M (2015) Allocation in LCAs of biorefinery products: implications for results and decision-making. J Clean Prod 93:213-221. https://doi.org/10.1016/j. jclepro.2015.01.013

Secchi M, Castellani V, Orlandi M, Collina E (2019) Use of lignin sidestreams from biorefineries as fuel or co-product? Life cycle analysis of bio-ethanol and pulp production processes. BioResources 14: 4832-4865. https://doi.org/10.15376/biores.14.2.4832-4865

Staffas L, Tufvesson L, Svenfelt Å, Åström S, Torén J, Arushanyan Y (2013) Alternative sources for products competing with forest based biofuel-a pre-study Contract No: Report:9

Svanström M, Heimersson S, Ekvall T (2017) Generating LCA partitioning factors for sewage sludge management using a Delphi procedure. In: Proceedings of the 12th Conference on Sustainable Development of Energy, Water, and Environment Systems, SDEWES2017. 0839, Dubrovnik, Croatia. pp 1-14

The Swedish Energy Agency (2017) Energiläget 2017

Tomani P (2010) The lignoboost process. Cell Chem Technol 44:53

Werner S (2017) District heating and cooling in Sweden. Energy 126: 419-429. https://doi.org/10.1016/j.energy.2017.03.052

Wernet G, Bauer C, Steubing B, Reinhard J, Moreno-Ruiz E, Weidema B (2016) The ecoinvent database version 3 (part I): overview and methodology. Int J Life Cycle Assess 40:1218-1230. https://doi. org/10.1007/s11367-016-1087-8

Yuan Y, Guo M (2017) Do green wooden composites using lignin-based binder have environmentally benign alternatives? A preliminary LCA case study in China. Int J Life Cycle Assess 22:1318-1326. https://doi.org/10.1007/s11367-016-1235-1

Publisher's note Springer Nature remains neutral with regard to jurisdictional claims in published maps and institutional affiliations. 